\title{
SEISMIC EMERGENCY PLANNING IN THE MUNICIPALITIES OF ELCHE AND ALICANTE, SPAIN: FIRST STEP FOR DISASTER MANAGEMENT
}

\author{
JOSE ANTONIO HUESCA-TORTOSA ${ }^{1}$, NOELIA AGEA-MEDINA ${ }^{2}$, SERGIO MOLINA-PALACIOS ${ }^{3}$, \\ JUAN JOSE GALIANA-MERINO ${ }^{4}$, JULIO ROSA-HERRANZ ${ }^{4} \&$ JUAN LUIS SOLER-LLORENS $^{3}$ \\ ${ }^{1}$ Department of Architectural Constructions, Polytechnic School, University of Alicante, Spain \\ ${ }^{2}$ MIES Ramóm Margalef, University of Alicante, Spain \\ ${ }^{3}$ Department of Earth Sciences and Environment, Faculty of Sciences, University of Alicante, Spain \\ ${ }^{4}$ Department of Physics, Systems Engineering and Signal Theory, Polytechnic School, \\ University of Alicante, Spain
}

\begin{abstract}
The south and south-east of Spain are the regions with a higher seismic hazard in Spain. However, although a regional normative focused on the importance of developing seismic emergency planning in many of the municipalities of the Valencian Community was established in 2011, only Elche and Alicante have started to compute the seismic risk and it is planned that their emergency plans will be finished before the end of 2019. The seismic hazard update in the region has shown that the main earthquake scenarios, which will hit both cities, correspond to the Crevillente and the Bajo Segura faults (also responsible of damaging historical earthquakes). The main goal of the developed emergency planning (PAM) is to provide a fast, effective and coordinate response from the public and private stakeholders when a damaging earthquake happen. Assuring, therefore, the maximum protection to the inhabitants and infrastructures in the urban area. The basic functions of the PAM are: a) To establish clearly the organizational and functional structure for intervention in emergencies due to earthquakes that affect the territory; b) To assure the coordination between the emergency agencies at the national, regional and urban level; c) To map a seismic risk zonation that can be used to plan the intervention and locate non-damage infrastructures to be used in the emergency; d) To Increase the population resilience through emergency procedure and education.
\end{abstract}

Keywords: emergency plan, seismic risk, seismic resilience, emergency management, disaster management.

\section{INTRODUCTION}

Great loss of human life, structural damage, and social and economic upheaval have occurred repeatedly in recent history due to such natural hazards as earthquakes, hurricanes, landslides, floods and tsunamis. Although earthquake disasters are a minority in comparison to other natural catastrophes, they are responsible of a $77 \%$ of fatalities and a $34 \%$ of overall losses. This is the reason why public authorities have to improve the planning and seismic policy for the earthquake-prone countries. This is the only way of reducing fatalities and losses.

Spain is a low to moderate seismicity country with historical damaging earthquakes as the 1829 Torrevieja earthquake (south-east of Spain) and the 1884 Andalucia earthquake (south of Spain), both with estimated magnitude higher than 6.0 [1]. Additionally, the M5.1, 2011 Lorca earthquake was the first one causing fatalities since the implementation of modern earthquake-resistant codes in Spain. Nine fatalities, thousands of displaced persons, significant damage to relatively recent buildings and elevated economic losses were the sad budget of this event. In this case, failures on construction conception and the poor performance of non-structural elements were behind this disaster [2].

On April 29, 2011, the government of the autonomous Valencian region approved the "Plan Especial frente al Riesgo Sísmico" (special plan against seismic risk) through the Order 44/2011. This Order promotes that, at least, 183 municipalities have to prepare 
their management and emergency plans against the inherent regional seismic risk. Amongst others, the objectives of those plans should not only include a detailed seismic hazard evaluation but also the analysis of the vulnerability of the existing building stock and the computation of earthquake loss scenarios in order to better prepare for emergency situations. However, currently, none of the municipalities have completed its emergency plan and only the municipalities of Elche and Alicante have given the first steps in order to have it ready before the end of 2019.

The mitigation policy to be established within a seismic emergency planning for any municipalities can be delineated by the following actions:

a) Define an organizational and functional structure that can intervene when an earthquake happens.

b) Take into consideration the coordination with other seismic emergency planning at a regional and national level.

c) Compute the seismic risk in the municipality and establish areas in terms of safeness that can be used in the emergency.

d) Settle the preparedness measures (including education).

e) Establish a database of any infrastructure agencies that can be available to act if an emergency starts.

Therefore, the goal of this paper is to summarize the steps given in Alicante and Elche towards an efficient emergency planning.

\section{SEISMIC EMERGENCY PLANNING IN SPAIN}

In Spain, since 1995 (according to BOE of May 25, 1995) there is a Basic Civil Protection Planning Directive against the Seismic Risk that was modified in 2004 (according to BOE of October 2, 2004) and which is implemented with the State Plan (March 2010), which is characterized as the Master Plan. Therefore, it establishes the general, organizational and functional aspects of the planning to be specified in the operational planning (coordination and support plans) and in specific action procedures.

This State Plan for Civil Protection against Seismic Risk aims to establish the organization and procedures of action of those State services and, where appropriate, other public and private entities, which are necessary to ensure an effective response to the different seismic situations that may affect the Spanish State.

From this Basic Directive and from the State Plan (Master Plan), the Special Plans are prepared for the seismic risk by those Autonomous Communities in whose territory there are areas where the seismic hazard, in terms of EMS-98 intensity is equal to or greater than VI, for a return period of 500 years, in accordance with the provisions of the Basic Civil Protection Directive against Seismic Risk (Table 1).

All the Autonomous Communities obliged to prepare their Special Plan for Seismic Risk have the same approved by the National Civil Protection Commission, and some of them also have also approved their respective update. This is the case of the Murcia autonomous community which was updated after the 2011 Lorca earthquake.

One of the most important result of these regional seismic emergency planning is that they allow to define the municipalities in which it is compulsory to develop a specific plan. This is done also using the corresponding threshold value of the seismic hazard obtained for each municipality (intensity VI or higher).

The Valencian Community (named Valencia in Table 1) is the case study of this paper because although the regional plan was approved in 2011, currently none of the 
municipalities have approved their specific plans and only Elche and Alicante have started its development (Fig. 1).

Table 1: Summary of seismic risk emergency plans approved and updated.

\begin{tabular}{|l|c|c|}
\hline Autonomous community & Approval date & Update date \\
\hline Cataluña & 05.06 .2002 & \\
\hline Baleares & 01.12 .2004 & \\
\hline Murcia & 19.07 .2006 & 29.10 .2015 \\
\hline País vasco & 10.07 .2007 & \\
\hline Andalucia & 16.12 .2008 & \\
\hline Extremadura & 28.04 .2009 & \\
\hline Canarias & 03.12 .2009 & 12.12 .2017 \\
\hline Aragón & 03.12 .2009 & \\
\hline Galicia & 03.12 .2009 & \\
\hline Valencia & 01.03 .2011 & \\
\hline Navarra & 21.07 .2011 & \\
\hline Castilla-La Mancha & 10.09 .2018 & \\
\hline
\end{tabular}

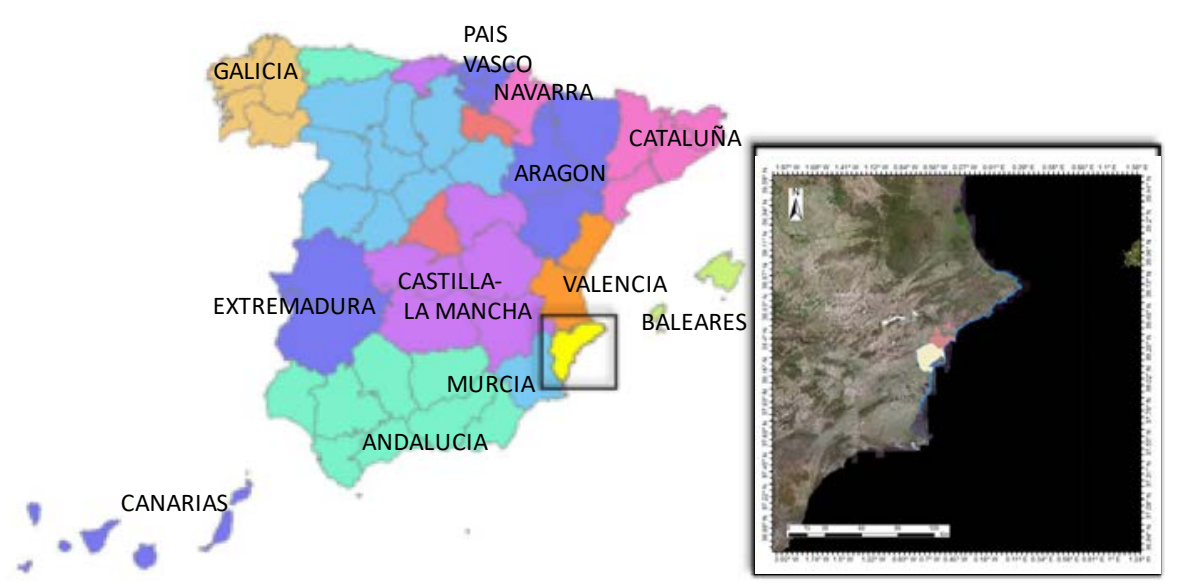

Figure 1: Autonomous regions with a seismic risk emergency plan approved. A detail of the Alicante province and the location of the municipalities of Elche (yellow) and Alicante (red).

\section{DEVELOPING A SEISMIC EMERGENCY PLAN FOR THE MUNICIPALITIES OF ELCHE AND ALICANTE}

\subsection{Seismic risk analysis}

A detailed seismic risk analysis has been carried out for the municipalities of Elche and Alicante using several scenarios that can hit both cities [3]. The Crevillente Fault will be the responsible of the two main earthquakes (Mw 5.5 and 6.5) that can affect severely the municipalities in terms of damage and losses. This fault runs along to the Internal and External Betic Zones contact, representing the former limit between the Eurasian and African 
plates. The CF fault zone and associated fold is $60 \mathrm{~km}$ long; the fault presents reverse kinematics (with a minor sinistral component) from the Tortonian [4]. This fault is also responsible of moderate earthquakes in the region, such as the 1787 Elche earthquake, with intensity VI in the EMS-92 scale, and the 1958 Fortuna earthquake (Mw 4.0 and intensity VI) and the 2018 Albatera earthquake with a Mw 4.2, widely felt in the city of Elche and Alicante. Besides, the maximum magnitude $(\mathrm{Mw})$ from length using empirical relationships is $6.79(6.67-6.79)$ [5].

Fig. 2 shows the computed ground motion in terms of PGA. As we can see, the ground motion decreases from north to south in Elche although in Alicante the ground motion is lower, due to the higher distance to the rupture, the variations in the soil conditions also introduce important variations in the PGA in the municipality. The PGA has a maximum of $0.23 \mathrm{~g}$ and $0.41 \mathrm{~g}$ in Elche for a Mw 5.5 and 6.5 respectively. On the other hand, the maximum PGA ranges from $0.11 \mathrm{~g}$ to $0.24 \mathrm{~g}$ in Alicante.
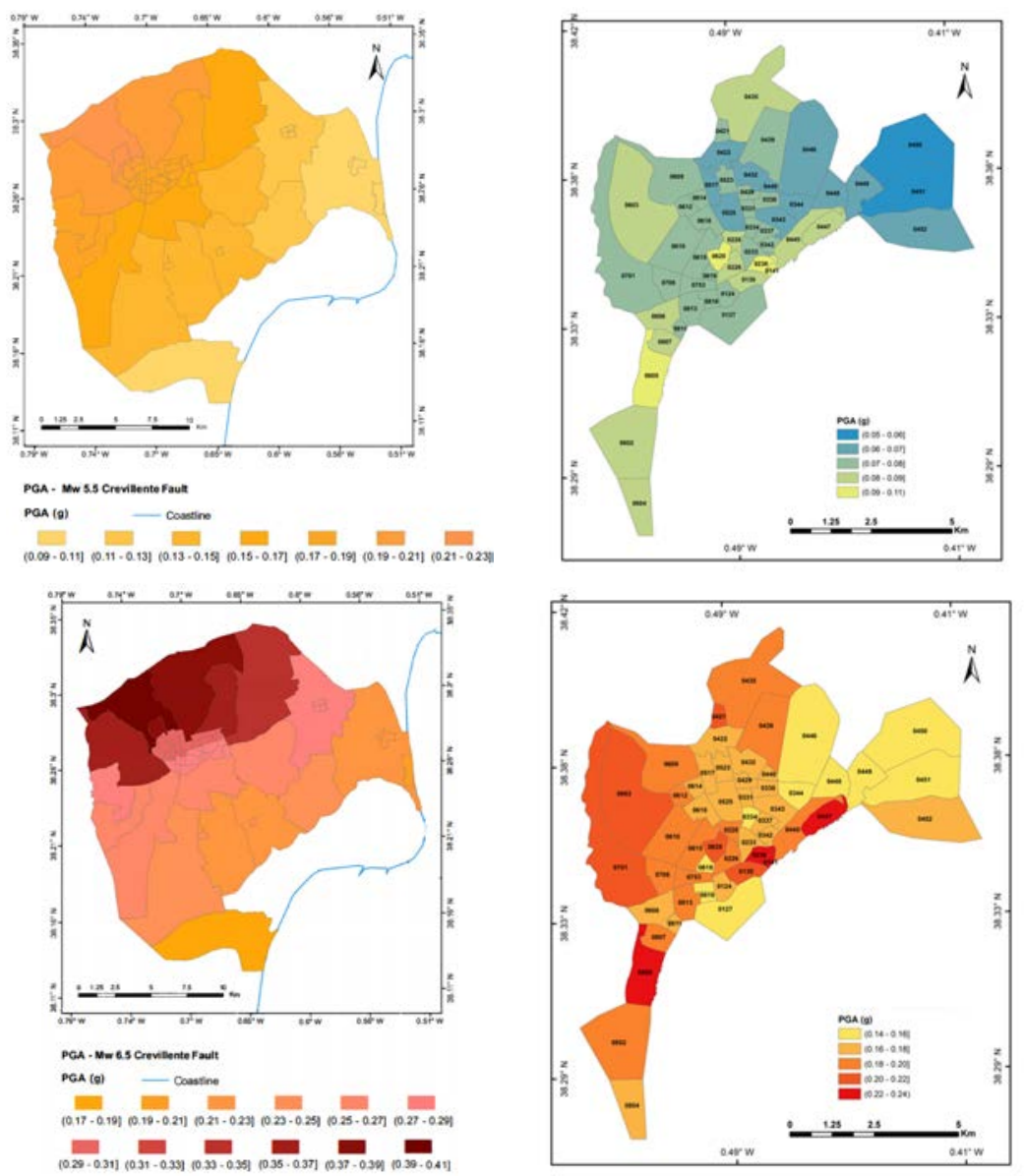

Figure 2: Ground motion scenarios of a magnitude 5.5 (top) and 6.5 (bottom) at the Crevillente Fault for Elche (left) and Alicante (right). (Source: Molina et al. [3].) 
As a summary, they found that $13 \%$ of the building stock in Elche and $0.7 \%$ in Alicante would be inhabitable after a Mw 5.5 earthquake (74\% in Elche and $18 \%$ in Alicante for a Mw 6.5) [3]. The homeless will range from $0.4 \%$ in Alicante to $17 \%$ in Elche for a Mw 5.5 and 8 to $82 \%$ for a Mw 6.5. The people injured (from slight injuries to even death) also ranges from $0.03 \%$ in Alicante to a $0.8 \%$ in Elche for a Mw 5.5 and from 1.7 to a $7 \%$ for a Mw 6.5. The economic losses will increase from $0.6 \%$ of the constructed value in Alicante for a $\mathrm{Mw}$ 5.5 to $45 \%$ of the constructed value in Elche for a Mw 6.5. Table 2 summarizes these results in terms of absolute values, and Fig. 3 represents the mean damage ratio (MDR in percentage) in each of the geounits corresponding to both municipalities. At the top, we can compare the impact for the magnitude 5.5 (left) and 6.5 (right) so we can see that some districts of the urban area are widely affected in both cases although the impact is obviously higher in the magnitude 6.5 (MDR of 68 to 88\%) and lower in the magnitude 5.5 (MDR of 15 to $22 \%$ ).

Table 2: Summary of the seismic risk results for both municipalities.

\begin{tabular}{|l|l|c|c|c|c|c|}
\hline Scenario & Municipality & $\begin{array}{c}\text { Uninhabitable } \\
\text { buildings }\end{array}$ & Homeless & $\begin{array}{c}\text { People } \\
\text { injured }\end{array}$ & $\begin{array}{c}\text { Economic } \\
\text { losses } \\
\text { (millions } €)\end{array}$ & $\begin{array}{c}\text { Mean } \\
\text { damage } \\
\text { ratio } \\
(\%)\end{array}$ \\
\hline \multirow{2}{*}{5.5} & Elche & 4576 & 40,013 & 1900 & 2300 & 10.3 \\
\cline { 2 - 7 } & Alicante & 178 & 1300 & 96 & 228 & 0.8 \\
\hline \multirow{2}{*}{6.5} & Elche & 25,534 & 190,085 & 15,800 & 13,500 & 63.0 \\
\cline { 2 - 7 } & Alicante & 4362 & 25,784 & 5304 & 6190 & 16.6 \\
\hline
\end{tabular}
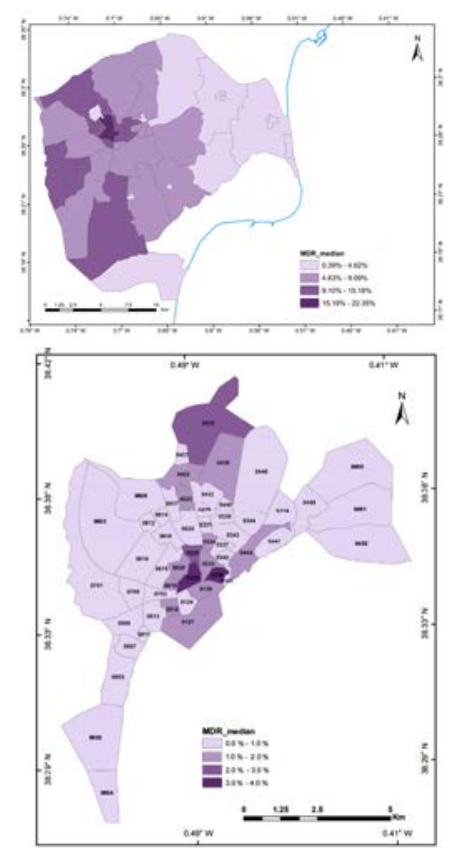
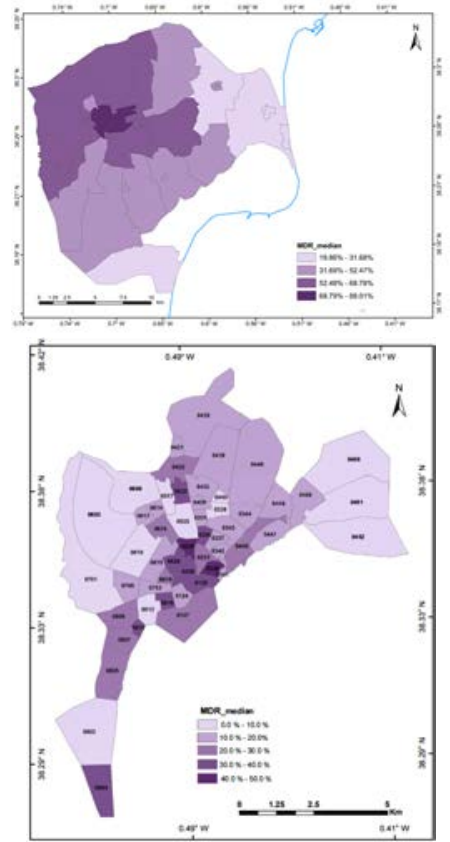

Figure 3: Impact of the magnitude 5.5 and 6.5 (Crevillente Fault) in terms of Mean Damage Ratio in Elche (top) and Alicante (bottom). (Source: Molina et al. [3]). 
Regarding the municipality of Alicante (Fig. 3 bottom) we observe the same behavior although as we saw with the ground motion the MDR distribution is quite heterogeneous due to the soil effect and vulnerability distribution in the municipality. For both magnitudes, the old urban area has the highest MDR, ranging from 3-4\% for Mw 5.5 to $40-50 \%$ for Mw 6.5 .

From the previous results, it was observed that even the Mw 5.5 which cause important damages in the municipality of Elche affect also the municipality of Alicante and the oldest districts of both cities with buildings constructed without any seismic regulations are the most affected [3]. Additionally, soil effects also have an important effect on damage distribution.

\subsection{Effectiveness and functionality}

The organizational structure of both municipalities of the province of Alicante, follow the scheme of the Basic Directive and State Emergency Plan for this special risk, as well as that of the Special Plan for the Seismic Risk of the Valencian Community. Identifying three levels of organization for the emergency: Strategic level (CECOPAL), Tactical Level (PMA) and Operational Level (BASIC UNITS).

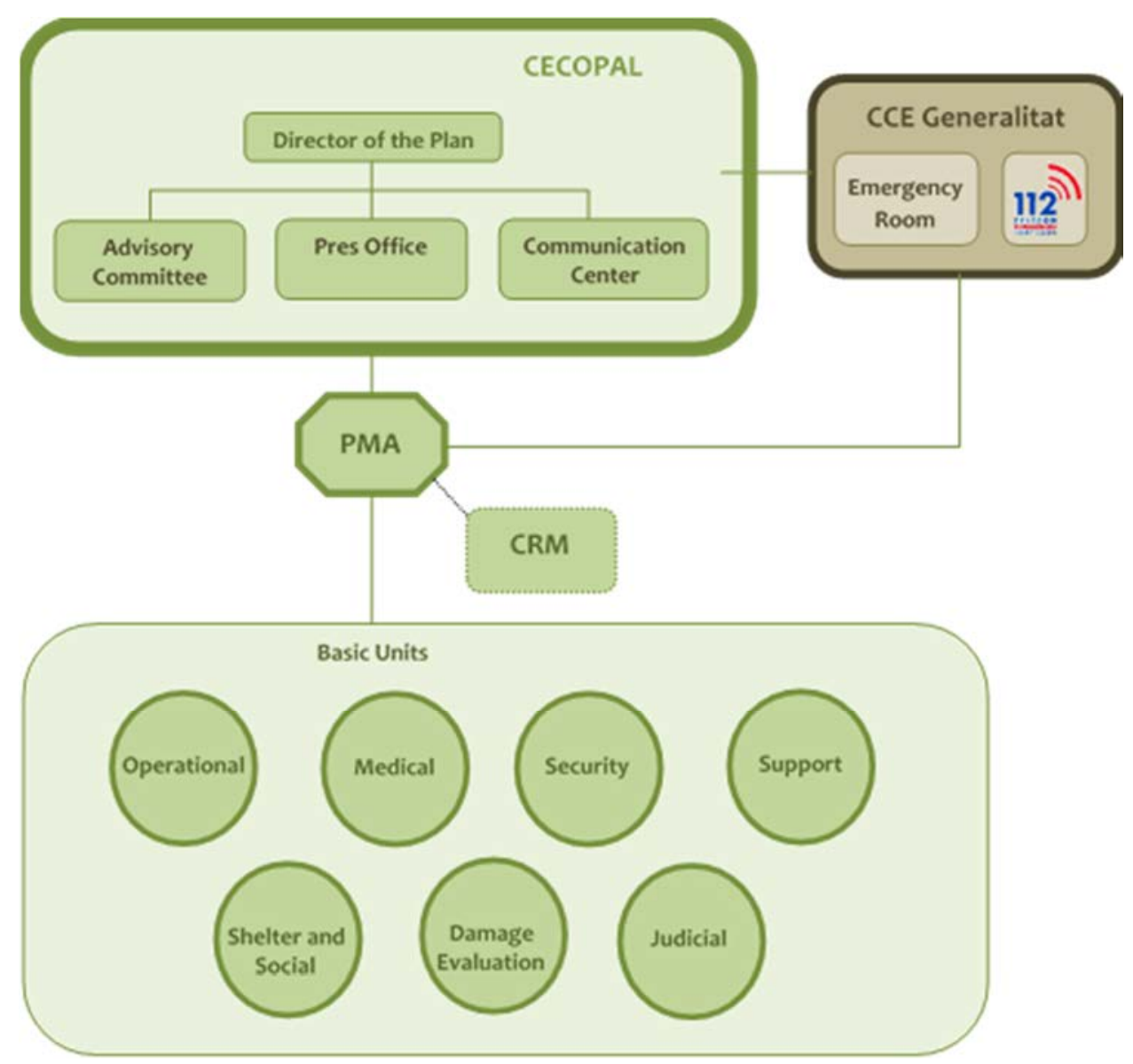

Figure 4: Functional organization schemes for emergency management against seismic risk in the municipalities. 
In the first level the CECOPAL (Municipal Operational Coordination Center) is organized with the Director of the Plan in charge, together with the Advisory Committee (Councilors and Headquarters of the Services / Areas affected, and a Panel of Experts), the Press Office and the Communication Center.

On a second level and depending on the severity and type of emergency, the PMA (Advanced Command Post) is made up with the leaders of the Basic Units mobilized by the Plan Management and in constant communication with the CECOPAL

Finally, the third level is composed by the Basic Units of services and people involved from the early stages of the emergency.

It is a very probable fact that both municipalities have to organize themselves, not only among themselves, but also in a broader scope with other municipalities also affected by the same earthquake. And in this way, it is very important that between municipalities there is a system of response and organization, on another scale, operational and effective. On this matter, we propose to take it into account in the development of the Municipal Action Plans and in the future revision of the Special Plan of the Valencian Community against seismic risk. Where a coordinated, operational and effective intermunicipal plan could be constituted.

\subsection{Resilience}

In the wider sense, resilience incorporates technical, organization, social, economic and environmental issues. The current goal of minimizing casualties and economic and functionality loss is extended to the requirement for the affected community or system to return to "normal" conditions within the shortest possible time. For both municipalities we have established some procedures developed to increase the population resilience:

a) A leaflet with procedure about what to do before, during and after an earthquake will be include to the seismic emergency planning so each municipality will be able to distribute it between the population and include it in its web page.

b) For each municipality, the urban planners will select "secure areas" as meeting points. These places will be marked with specific signs and the population will be instructed to safely walk towards these areas if an earthquake happens. Unfortunately, many of the injuries to the population during the 2011 Lorca earthquake happened because they stood close to the buildings so they were hit by falling object.

c) Greater control and surveillance over the non-structural elements that can affect, with the fall to the public highway, the safety of the population and the functionality of the evacuation routes.

d) The municipality will establish a set of conferences and educational programs on earthquake protection devoted to schools and population. The enhancement of the information of the population to seismic risk may serve a better response on how and what to do if it happens.

e) Finally, the urban planner will also use the microzonation results in order to establish local normatives to avoid the soil-structure resonance by limiting the number of stories according to the predominant period of the soil and the fundamental period of the designed buildings.

f) With the revision of some constructive details provided by the national seismic-resistant norm, perhaps some damage due to affection between structures could be reduced.

g) The realization of joint exercises between municipalities, which, probably due to their proximity, can be affected by the same earthquake, could contribute to a better knowledge of the resources and technical and human resources, and to an efficiency in the operability between them. 


\section{CONCLUSIONS}

Risk management planning for seismic disaster is an integral part of the municipality policies aiming at creating a resilient community. Some initiatives have to be taken in order to increase the local communities' preparedness level, for example, divulgative workshop to the population, meetings with the civil protection and authorities at a local and regional levels, pilot exercises, etc. Although there are many issues to be solved, the seismic emergency planning of Alicante and Elche are great steps forward because they have made possible the updating of procedures, the reactivation of many processes related to earthquake preparedness and the establishment of a starting point in terms of resilience improvement.

\section{ACKNOWLEDGEMENTS}

The present research has been funded by the Ministerio de Economia, Industria y Competitividad (CGL2016-77688-R AEI/FEDER,UE), the Generalitat Valenciana (AICO/2016/098) and the cooperation and funding of the Elche and Alicante municipalities.

\section{REFERENCES}

[1] Molina, S. et al., Seismic risk scenarios for the urban area of Almoradi (Southeast Spain). Proceedings of the 8th International Workshop on Seismic Microzoning and Risk Reduction, 2009.

[2] Navarro, M., García-Jerez, A., Alcalá, F.J., Vidal, F. \& Enomoto, T., Local site effect microzonation of Lorca town (SE Spain). Bulletin of Earthquake Engineering, 12, pp. 1933-1959, 2013.

[3] Molina S. et al., Seismic damage scenarios in the municipalities of Elche and Alicante (Spain): A first step to the emergency planning. International Journal of Safety and Security Engineering, 1-2, 2019 (in press).

[4] Martin-Rojas, I., Alfaro, P. \& Estevez, A., 3D geometry of growth strata in a faultpropagation fold: insights into space-time evolution of the Crevillente Fault (AbanillaAlicante sector), Betic Cordillera, Spain. International Journal of Earth Sciences, 104(5), pp. 1387-1404, 2015.

[5] Stirling, M., Rhoades, D. \& Berryman, K., Comparison of earthquake scaling relations derived from data of the instrumental and preinstrumental era. Bulletin of the Seismic Society of America, 92(2), pp. 812-830, 2002. 